\title{
A INTERPRETAÇÃO DA VELHICE DA ANTIGUIDADE ATÉ O SÉCULO XXI
}

\author{
Marcelo Henrique de Jesus Flores Sobrinho ${ }^{1}$ \\ Neila Barbosa Osórioº
}

\begin{abstract}
RESUMO
O estudo é um recorte da dissertação de Mestrado em Educação (UFT) aprovada pelo Comitê de Ética em Pesquisa sob n ${ }^{\circ} 15606519$. 6.0000.5519. Estudo com cunho qualitativo e revisão de literatura. Este estudo objetiva apresentar fragmentos históricos a partir da interpretação de alguns filósofos sobre a velhice. É evidente que a velhice e o envelhecimento ainda são tabus em nossa sociedade. Portanto, apresentar estes fragmentos históricos é de suma importância para o mundo contemporâneo. Conclui-se que, há entendimentos e valoração diferentes, dependendo da sociedade, no entanto, é unânime dar importância de ser e estar velho, haja vista que, na atualidade, chama-nos a atenção a preparação das gerações para a velhice, para a construção de um envelhecimento digno, participativo e ativo na sociedade, foco das Universidades- UNATIs e UMA, da Gerontologia e Geriatria, - áreas da Medicina que estudam e tratam o envelhecimento humano, respectivamente.
\end{abstract}

Palavras-Chave: Antiguidade. Conhecimento histórico. Modernidade. Velhice.

\begin{abstract}
The study is an excerpt from the master's Dissertation in Education (UFT) approved by the Research Ethics Committee under $\mathrm{n}^{\circ} 15606519$. 6.0000.5519. Qualitative study and literature review. This study aims to present historical fragments from the interpretation of some philosophers on old age. It is evident that old age and aging are still taboo in our society. Therefore, presenting these historical fragments is of paramount importance for the contemporary world. It is concluded that there are different understandings and valuations, depending on the society, however, it is unanimous to give importance to being and being old, given that, at present, we call attention to the preparation of generations for old age, for the construction of a dignified, participative and active aging in society, the focus of Universities- UNATIs and UMA, Gerontology and Geriatrics, - areas of Medicine that study and treat human aging respectively.
\end{abstract}

Keywords: Antiquity. Historical knowledge. Modernity. Old age.

Data da submissão 23.11 .2020

Data da aprovação 08.02.2021

\section{INTRODUÇÃO}

A velhice e o envelhecimento são processos que se dão naturalmente no decorrer da vida de todo e qualquer ser vivo e ocorrem de formas diferentes, influenciadas por outros fatores (ambientais, climáticos, alimentares, sociais e econômicos), pois cada animal ou indivíduo é

\footnotetext{
${ }^{1}$ Possui Graduação em Serviço Social pela Universidade Federal Do Pará - Ufpa (1998). Especialista Em Saúde Pública, Pela Faculdade De Tecnologia Internacional - Fatec (2005). Pós-Graduação Lato Sensu Em Educação Social e Docência do Ensino Superior, pela Faculdade Mantenense dos Vales Gerais - Intervale (2016). Atualmente é Assistente Social da Prefeitura de Conceição do Araguaia (Sul do Pará) e Técnico em Gestão Pública da Educação - Secretaria de Estado de Educação do Pará. Mestre em Educação pela Universidade Federal do Tocantins - UFT. E-mail: marcelobelemss@gmail.com

2 Doutora em Ciência do Desenvolvimento Humano (UFRS). Docente da UFT. E-mail: neilaosorio@uft.edu.br
} 
um ser biológico exclusivo com suas peculiaridades. Na nossa pesquisa, o objeto de estudo está relacionado à velhice dos homens (OLIVEIRA, et al, 2011).

Numa análise sociológica, a velhice humana apresenta-se de forma ambígua, ou seja, é vista como sinônimo de sabedoria e prestígio, mas também como fase de decrepitude e uma fonte de sofrimentos, evidenciada como um momento de felicidade para alguns e de tristeza para outros. Esta dualidade do próprio conceito do que é a velhice na sociedade humana se dá de forma diferente em cada ser, logo, concluímos que o envelhecimento se reificará no indivíduo conforme os seus hábitos e costumes particulares no decorrer de sua existência e, dependendo principalmente do seu estado de saúde, do seu modo de viver a vida, poderá ser algo positivo ou negativo no seu existir, o que dependerá em parte do próprio indivíduo em suas escolhas, enquanto ser vivo, participante no e do mundo físico (CÍCERO, 1999; 2006).

Desta forma, o animal racional, em sua formação humana, tem um tempo de vida neste mundo, com início, meio e fim, o que podemos resumir em duas etapas: a primeira é o nascimento e a segunda a morte. A formação humana se dá nas quatro fases do desenvolvimento: na infância (do nascimento até os 11 anos de idade), em seguida, na adolescência (que vai dos 12 aos 20 anos de idade), posteriormente, na fase adulta (a partir dos 21 anos de idade) e, finalmente, na velhice, fase considerada, nos países em desenvolvimento, a partir dos 60 anos e nos desenvolvidos, iniciando aos 65 anos. Em outras palavras, vivemos uma vida biológica constituída de quatro fases distintas, com suas características físicas e/ou psicológicas diferentes, sendo elas: a infância, em seguida a adolescência, a idade adulta e a velhice. Como podemos perceber o homem, desde o seu nascimento até a sua morte, é um ser inserido em um processo de formação do caráter humano, de sua identidade cultural e social.

Portanto, o envelhecimento humano é universal e inevitável, processo que é vivido e sentido de formas diferentes por cada ser vivo. A velhice é intrínseca à própria natureza humana, e todo e qualquer ser humano logo se deparará com esta fase da vida. Conseguir atravessar a infância, a juventude, a fase adulta e assim chegar à maturidade é muito relevante, entretanto, a grande maioria não se preocupa e nem se prepara para a chegada da velhice e, sobretudo, para viver um envelhecimento ativo e saudável.

Nas civilizações antigas, havia uma preocupação com a velhice e com o rejuvenescimento. Essa apreensão persiste até a contemporaneidade, todavia, apesar do mundo ter evoluído cientificamente e tecnologicamente, ainda não se encontrou a "fórmula milagrosa", ou a tão sonhada "fonte da juventude" que é vislumbrada em diversos filmes hollywoodianos. Portanto, não há como determos a velhice. Precisamos entender que é um processo natural e biológico da criação dos seres vivos, em especial, dos humanos, que devem aceitá-la e prepararem-se para um envelhecimento ativo e digno na sociedade, haja visto que este processo humano é inevitável.

\section{LAO-TSÉ (604 - 531 A. C.), O “VELHO MESTRE" E A VELHICE.}

Para aprofundarmos a temática do envelhecimento humano, verificamos, por meio de pesquisas, que na China, desde a antiguidade até a contemporaneidade, velhice é sinônimo de sabedoria e respeito à família, segurança dos anciãos, o que evidencia uma educação e cultura milenar (tradição) de cuidar bem de seus velhos que são considerados como pessoas de imenso valor na sociedade chinesa.

Dessa forma, na antiga China, destacamos alguns filósofos que conceituaram a velhice, dentre os quais Lao-Tsé (604 - 531 a. C.) que foi o fundador do Taoísmo, doutrina mística e filosófica (formulada no séc. VI a.C.) que enfatiza a vida em harmonia com o Tao (termo chinês que significa "caminho", "via" ou "princípio"), o todo e único. Pouco se conhece sobre a história da vida do Filósofo chinês Lao-Tsé ou Lao-Tzy, nome que, em sua tradução mais adequada, significa "ancião", "velho sábio", "grande senhor" ou "velho mestre", porém seu nome 
verdadeiro seria Li Er ou Lao Dan, mas ele se fez conhecido mundialmente através da sua obra intitulada "Da Razão Suprema e da Virtude, o Tao te King", livro escrito entre 350 e 250 a. C. e que faz parte da literatura chinesa (TAO TE CHING, 2011; LAO TZU, 2014).

Para Lao-Tsé, a velhice era entendida como uma vivência, um momento supremo de alcance espiritual máximo e que o ser humano, ao chegar à idade de 60 anos, estaria próximo do momento de liberta-se do seu corpo físico, para viver o êxtase da sua passagem à santidade (a dimensão espiritual). De acordo com o Filósofo Lao-Tsé, a velhice é reconhecida apenas no outro indivíduo humano e não em quem a vivencia, o detentor do corpo que envelhece, conectado na dimensão temporal da existência que se vislumbra a cada instante, de forma renovada, vive uma transformação, visando novos limites, no sentido de adentrar com a alma pura no mundo metafísico (da santidade), o que seria uma evolução transcendental nesta etapa da vida (TAO TE CHING, 2011; LAO TZU, 2014).

\section{O FILÓSOFO CONFÚCIO E A VALORIZAÇÃo DA VELHICE HUMANA NA CHINA.}

Na China, também, há uma filosofia com base nos ensinamentos do Mestre Confúcio que valoriza os velhos e ensina que todas as famílias deveriam obedecer aos idosos, manifestando respeito pelas gerações mais velhas. Confúcio (551 - 479 a.C.) era um filósofo da civilização oriental, considerado, por muitos, um homem sábio, com enorme conhecimento sobre a alma humana e que construiu conceitos filosóficos relacionados à moral, à ética e à sabedoria. O Confucionismo não pode ser confundido com religião, haja visto que se trata de uma organização nacionalista da sociedade, respaldada no princípio da simpatia universal, que deve ser atingida pela educação e prolongando-se do ser humano à família e da família ao Estado, sendo este último a maior família (CONFÚCIO, 1999).

Nesta perspectiva, os ensinamentos de Confúcio, os Lun Yú, vulgarmente conhecidos por "Anacletos" foram compilados pelos seus discípulos após a sua morte. O objetivo essencial da vida humana é, segundo Confúcio, a perfeição, partindo do desenvolvimento da natureza individual e atingindo a criação de Estado bem ordenado e um mundo pacífico. Esta ideia é o "jen", a palavra que significa "benevolência", "bondade", "verdadeira humanidade". A humanidade é o pilar central do Confucionismo, no qual se acredita que todos os humanos são naturalmente bons, sendo a educação o fator principal que irá determinar a condição humana. Assim, o Confucionismo trabalha uma filosofia, enquanto doutrina que conciliará a natureza humana com teorias políticas e sociais, visando o bem viver na sociedade.

Na estrutura da Filosofia de Confúcio, a família é a base e todos os membros do grupo familiar devem obediência ao ser humano masculino mais velho. Desta forma, a autoridade do patriarca mantém-se com o passar dos anos e até mesmo a mulher, que sempre foi subordinada, em sua velhice, ganha poderes maiores do que os jovens masculinos, exercendo grande influência na educação dos netos. Confúcio (1999) percebia os velhos como pessoas com grande autoridade e sabedoria e declarava que aos 60 (sessenta) anos o ser humano passa a compreender sem a necessidade de refletir tudo o que ouve e, a partir dos 70 (setenta) anos, o indivíduo segue os desejos de seu coração, sem violar regra alguma. Confúcio orientava a sociedade a prestigiar os velhos e a velhice e afirmava que o processo de envelhecimento do homem deveria ser com paz e felicidade, exigindo dos mais jovens, o amor e o respeito para com os anciãos, os antigos, os seus pais e avós no seio familiar e na sociedade.

Confúcio (1999) dizia que no mundo não há nada maior do que a criação humana e, no ser humano, nada é maior que a piedade filial. A filosofia Confucionista afirma que os filhos têm deveres e obrigações perante seus pais, o que pressupõe: amá-los, cuidá-los com carinho e atenção durante a vida inteira, visando torná-los pessoas felizes, de diversas formas e em todos os momentos em suas existências no bojo familiar e, ainda, demonstrarem saudade e dó deles, 
em virtude da morte e posterior a ela, reverenciando-os, como culto aos antepassados, o que seria a única ligação dessa doutrina com o mundo espiritual.

Nesta perspectiva, o amor dos filhos aos pais envelhecidos é algo divino, especial, que compreende maior proteção e segurança na última fase da vida humana, o que se considera um dos mais admiráveis atos da raça humana consigo mesma e para com seus semelhantes, em destaque, com a sua geração e para com as futuras gerações (SANTOS, 2001).

Para Confúcio (1999), o homem velho é um ser imerso no conhecimento e com grandes experiências vividas a serem repassadas aos mais jovens que lhes devem respeito. Assim, a velhice pressupõe autoridade que se justifica pela sabedoria presente nos velhos que têm muito a ensinar aos novos.

\section{A VELHICE NA SOCIEDADE JAPONESA}

No Japão, da antiguidade até a modernidade, a velhice sempre foi e continua sendo vista, assim como na China, sinônimo de sabedoria e respeito aos velhos. Estes são vistos, de fato, como pessoas de grande autoridade na sociedade japonesa. Dessa forma, a velhice e o envelhecimento humano, para os japoneses, são fenômenos naturais e inerentes à nossa espécie, que devem ser avaliados, cuidados e estudados com muita atenção pelos governantes, ressaltando que as pessoas idosas devem ser tratadas com carinho, amor, respeito e dignidade, devido à vasta experiência acumulada em suas existências.

A família é considerada como referência fundamental no cuidado dos velhos, haja vista ser o porto seguro do idoso, sendo os familiares: os filhos, os netos e os mais jovens, aqueles que irão ser educados para cuidar bem de seus pais e avós, o que significa, ainda, tratar deles próprios, já que mais tarde serão velhos também. Os jovens japoneses são inseridos pela família em um processo de ensino-aprendizagem construído nos lares que os educa para viverem e demonstrarem sempre alegria, fraternidade, festa e plenitude pela presença dos velhos em seu meio familiar e social (CONFÚCIO, 1999).

A Sociedade Japonesa, particularmente, apresenta uma educação de dignidade e respeito, uma cultura milenar, passada de geração a geração, no sentido de cuidar bem, glorificar e cultuar seus velhos, o que sem dúvida, é algo muito valioso e de prazer para as pessoas da chamada terceira idade. Destaca-se que os japoneses antes de tomarem qualquer decisão acerca de determinadas situações, aconselham-se com os anciãos, por considerarem seus conselhos sábios e experientes e estes, também, têm grande influência e atuação nas decisões importantes nos grupos sociais em que fazem parte, inclusive, alterando as agendas e o destino da política de seu país (PESSANHA, 2006).

\section{A VELHICE E O ENVELHECIMENTO NAS SOCIEDADES OCIDENTAIS}

A palavra Ocidente vem do latim occidens, que significa "pôr do sol", oeste, que difere do oriente. O chamado "Mundo Ocidental", "Civilização Ocidental" ou "Ocidente", são nomenclaturas que abrangem um conceito geopolítico e cultural, associadas primeiramente à Europa Ocidental e que, posteriormente, se estendeu a outras regiões do mundo com o processo de colonização, onde essas áreas têm uma população representativa de ascendência europeia, de forma que suas culturas e sociedades são fortemente influenciadas pela Europa. Nesta perspectiva, na contemporaneidade, o mundo ocidental inclui a maior parte da Europa, além de muitos países de origem colonial europeia nas Américas e na Oceania, como Estados Unidos, Canadá, México, Argentina, Brasil, Chile, Austrália, Nova Zelândia, entre outros.

Beauvoir (2018), em seu livro "A Velhice", destaca que, na civilização ocidental, por volta do ano 2.500 a. C., a beleza e o vigor físico eram atributos humanos poetizados e aclamados, mas foi nesse período que surgiu o primeiro texto sobre a velhice, escrito no Egito, 
pelo poeta e filósofo Ptah-Hotep que evidenciou o envelhecimento como um estado de dependência dos idosos em relação aos jovens, e afirmou:

\begin{abstract}
Como é penoso o fim de um velho! Ele se enfraquece a cada dia; sua vista cansa, seus ouvidos tornam-se surdos; sua força declina; seu coração não tem mais repouso; sua boca torna-se silenciosa e não fala mais. Suas faculdades intelectuais diminuem, e lhe é impossível lembrar-se hoje do que aconteceu ontem. Todos os seus ossos doem. As ocupações que até recentemente causavam prazer só se realizam com dificuldade, e o sentido do paladar desaparece. A velhice é o pior dos infortúnios que pode afligir um homem. O nariz entope, e não se pode mais sentir nenhum odor (BEAUVOIR, 2018, p. 97).
\end{abstract}

Verificamos que Ptah-Hotep sinaliza e considera que a velhice é uma fase cruel da vida do ser humano, a qual o indivíduo enfrentará, quando chegar nela, haja vista que passará por momentos de dependência, dificuldades físicas, biológicas e mentais, terá diversas enfermidades e não terá boas condições e saúde. A visão deste filósofo não é muito agradável aos nossos olhos e pode até ser vista de forma preconceituosa, já que, em sua época, se privilegiava a beleza, o vigor físico e a juventude. Porém, não podemos negar em nossa contemporaneidade a velhice, fenômeno do envelhecimento que é uma realidade concreta em todos os continentes e em evolução constante no mundo.

Desta forma, em todas as sociedades, o número de pessoas velhas com sessenta ou mais anos de idade cresce rapidamente, ano após ano, conforme estatísticas. Percebe-se que há um grande contingente de velhos na modernidade que vivem em condições semelhantes às vislumbradas no texto do poeta e que a velhice organicamente representa declínio, mas que ocorre de formas diferentes nos indivíduos e de acordo com a condição social e econômica nas quais se encontram, sendo a pobreza extrema (vivenciada por grande parte dos velhos) um dos fatores determinantes para um processo de envelhecimento penoso, não saudável, não ativo e temido pela humanidade.

Na Antiga Grécia, dos anos de 4.000 a 1.000 a.C., o país de relevo montanhoso e com planícies entre as montanhas, com diversas ilhas e de clima árido, as cidades do mundo grego se desenvolviam, entretanto, duas cidades-estados das mais importantes brigaram pela supremacia dessa civilização e destacaram-se neste período: Atenas e Esparta. Estas tinham hábitos e costumes próprios, economias independentes e diferentes culturas, que geraram uma rivalidade entre essas cidades-estados, porém, formavam um povo que falava a mesma língua e que cultuava os mesmos deuses. Nesta perspectiva, a principal diferença entre Atenas e Esparta está no Modelo de Governo da cidade-estado, o que representa a diversidade cultural grega: Atenas consolidava a Democracia, enquanto Esparta efetivava uma Monarquia (Aristocracia).

Em relação à educação dos jovens, tanto os atenienses como os espartanos possuíam a mesma preocupação, mas realizavam-na de forma diferente. Atenas priorizava na educação o estudo da filosofia, da matemática e outras áreas do conhecimento. O saber era vital para toda e qualquer ação. A educação ateniense refletia os anseios e valores daquela sociedade, que tinha como objetivo principal a formação de indivíduos completos, ou seja, com bom preparo físico, psicológico e cultural. Por volta dos sete anos de idade, o menino ateniense era orientado por um pedagogo. De outro modo, Esparta efetivava uma educação rudimentar nos seus colégios militares, onde se aprendia a ler e escrever o básico e o necessário para a vida cotidiana, haja vista que se priorizava o corpo, visando transformar os jovens em guerreiros para as batalhas.

Atenas e Esparta travaram, entre os anos de 431 a 404 a.C., a Guerra do Peloponeso (conhecida como Guerra Mundial da Antiga Grécia) que foi detalhada em relatos de dois historiadores da Grécia Antiga: Xenofonte e Tucídides. Os espartanos deram suporte a um golpe oligárquico em Atenas, derrubando o Sistema Democrático e implantando um Sistema de Governo autoritário, conhecido como Tirania dos Trinta. Após muitos anos de batalhas, Esparta 
saiu vitoriosa, o que coincidiu com o declínio de Atenas. Todavia, Atenas ofertou ao mundo a Filosofia, a Democracia e outros conhecimentos, deixando-nos um grande legado. Atenas foi considerada o centro cultural e intelectual do Mundo Ocidental e, ainda, nos presenteou com os grandes filósofos, dentre eles: Sócrates, Platão e Aristóteles (PLATÃO, 1985).

A história do mundo grego evidencia a diversidade cultural entre as cidades-estados da Grécia Antiga, bem como, a política, a filosofia e a educação no bojo das cidades, a luta pela conquista de territórios, poder e direitos, em uma civilização que se tornou modelo para outras sociedades na modernidade. Entretanto, naquela época, a sociedade vivia com seus preconceitos em relação à velhice e cultuava a juventude, o corpo e a beleza. A senescência, ou seja, o processo do envelhecimento era algo detestável, deplorável, não desejável e pouco abordado na sociedade grega, o que não é tão diferente da nossa contemporaneidade, apesar da evolução da Ciência, da Medicina e da Tecnologia, em especial, da Gerontologia e da Geriatria.

A Gerontologia é a área da saúde multidisciplinar, onde diferentes profissionais da saúde desenvolvem estudos sobre o envelhecimento humano, levando em consideração as consequências físicas, emocionais, econômicas e sociais intrínsecas ao desenvolvimento da velhice no decorrer da vida e, deste modo, contribuindo para a prevenção e intervenção na saúde do idoso, com o objetivo de garantir uma melhor qualidade de vida para os velhos. A Geriatria é uma especialidade médica que estuda e trata das doenças ligadas ao envelhecimento. $\mathrm{O}$ médico geriatra é o profissional responsável pela promoção da saúde, prevenção e tratamento de enfermidades de pessoas que estão na chamada terceira idade.

Dessa forma, mesmo com todos esses avanços no que tange aos cuidados com os velhos, desde a Grécia Antiga até a modernidade, a questão social do envelhecimento ainda é pouco trabalhada, estudada e pesquisada nas sociedades capitalistas, haja vista que estas também cultuam a juventude, a beleza, o corpo escultural, o novo, em detrimento ao velho, e por considerarem os velhos como peças descartáveis no processo da produção e reprodução do capital, como se esses fossem engrenagens que não servem mais para a acumulação de riquezas, por não serem mais belos e por não produzirem, conforme as exigências e os desejos das grandes corporações ou empresas, ou seja, por serem vistos não mais produtivos para a enorme máquina do Capital globalizado.

Assim, a velhice e o envelhecimento, tanto nas cidades da antiga Grécia, como nas cidades do atual mundo moderno colonizado e capitalizado, são vistos de forma idêntica: algo negativo, uma coisa ruim e que para muitos expressam terror, como se a velhice não fosse atingir a todos. Por outro lado, existem outras visões de caráter positivo, exemplificados a seguir:

A filósofa, intelectual, ativista e professora Simone Beauvoir (1908 - 1986) em sua obra "A velhice", descreve o fenômeno social do envelhecimento de forma profunda. A escritora avalia e sinaliza diversos conceitos de importantes pensadores e poetas daquele período na Antiga Grécia, onde a velhice era vista dialeticamente de forma ambivalente, isto é, tanto positiva como negativa:

Segundo Homero, entretanto, a velhice está associada à sabedoria, e é encarnada em Nestor, o conselheiro supremo; o tempo lhe conferiu a experiência, a arte da palavra, a autoridade. Entretanto, ele aparece como fisicamente enfraquecido. E não é ele quem assegura aos gregos à vitória. Só um homem na força da idade seria capaz de inventar um artificio mais eficaz do que todas as táticas tradicionais. [...]. Por outro lado, Homero zomba dos demogerontes de Troia. Ele evoca o "limiar maldito da velhice". Num hino que lhe é atribuído, Afrodite diz: "Os deuses também odeiam a velhice." (BEAUVOIR, 2018: p. 104).

Na Jônia voluptuosa e hedonista, Minermo, sacerdote em Cólofon, exprime, por volta de 630 a.C., os sentimentos de seus concidadãos; ele canta os prazeres, a juventude, o amor; e detesta a velhice: "Que vida, que prazeres, sem Afrodite de ouro?" Ele lamenta Títono: "Infeliz dele! Foi com um mal imortal que os deuses o atingiram!" Repete sem cessar que preferiria morrer a envelhecer: "Como as folhas que a estação 
das flores faz brotar sob os raios do sol, durante um fugidio instante gozamos a flor de nossa juventude, e logo as negras Parcas nos cercam, uma trazendo a dolorosa velhice e a outra a morte. $O$ fruto da juventude não tardou a apodrecer: mal dura $o$ tempo da luz do dia. (BEAUVOIR, 2018, p. 105).

Como Minermo, Anacreonte, também ele originário da Jônia, cantou, no Século VI, o amor, o prazer, o vinho, as mulheres; envelhecer é perder tudo o que fazia a doçura de viver; ele descreve com dor o reflexo que seu espelho lhe devolve: cabelos fanados, têmporas grisalhas, dentes estragados, e se lamenta da morte próxima. [...]. Já vimos: à atitude dos poetas diante dessa aventura individual que é, para eles, a velhice, opõem-se as ideologias que consideram esta última uma categoria social. É assim Sólon rejeita a ideia melancólica que Minermo faz da idade avançada. Ele lhe responde que é desejável viver até 80 anos: "Eu não cesso de aprender, enquanto avanço na minha velhice." É que seu sistema de valores era bem diferente. A volúpia dos prazeres pouco contavam, para ele. Seu problema era político. Pretendia arbitrar entre os eupátridas e os tetas: na verdade, ele favoreceu a aristocracia. Como todos os conservadores, desejava apoiar-se nos anciãos e reservar a estes um grande espaço na construção da Pólis. (BEAUVOIR, 2018, p.106).

Não há como negar que a velhice, tanto no passado, como no presente, em sua concreticidade, representa, para muitos, uma fase terrível da vida humana, que inclusive é negada e invisibilizada pela maioria da população e por grande parte dos governos conservadores. Geralmente, a velhice é vista nos outros, jamais em nós mesmos. Entretanto, outros conceitos e de forma positiva foram sendo criados, no decorrer do tempo e conforme o avanço da humanidade, por aqueles que enxergam a velhice e o envelhecimento como etapas da vida humana absolutamente normal, como processos aos quais temos que aceitá-los.

Desse modo, adaptarmo-nos a esta nova fase do existir humano requer cuidados e mudanças de hábitos, em especial, no tratamento da nossa saúde e, além disso, em outras áreas: sociais, esportivas e educativas, nas quais a participação e inserção dos velhos são essenciais para o bem-estar social e para a melhoria da qualidade de vida deles. Atualmente, chamam-nos a atenção algumas áreas específicas da Medicina e da Educação, cujo foco está relacionado à preparação das gerações para a velhice, para a construção de um envelhecimento digno, participativo e ativo na sociedade: a Gerontologia, a Geriatria, as Universidades da Terceira Idade - UNATIs e a Universidade da Maturidade - UMA.

O filósofo Platão (427 a.C. - 347 a.C), que foi discípulo de Sócrates, a quem considerava o mais sábio e o mais justo dos homens, contempla a velhice em seu pensamento filosófico afirmando que o processo de envelhecimento é uma etapa da vida repleta de paz e tranquilidade, e em sua obra "A República", Platão revela passagens nas quais o seu mestre Sócrates faz referências ao envelhecimento, citando "que para os seres humanos prudentes e bem preparados, a velhice não constitui peso algum."

$\mathrm{Na}$ modernidade do mundo capitalizado, percebemos que a velhice, fenômeno mundial do envelhecimento, está em evolução e tem sido cada vez mais abordado pelas mídias, em manchetes de jornais, programas televisivos e na Internet. A velhice também é um tema evidenciado na área educacional, em especial, nas Universidades, no ensino superior, onde diversos especialistas e estudiosos têm chamado a atenção, reivindicando das autoridades governamentais planejamento e efetivação de políticas públicas direcionadas à população idosa, o que tem contribuído significativamente para a melhoria da qualidade de vida dos velhos e para a realização de debates no âmbito da comunidade acadêmica e na sociedade, em destaque, a brasileira.

Desta forma, entendemos que é fundamental e benéfico tanto para os governos, como principalmente, para os velhos e a sociedade, o desenvolvimento de projetos educacionais tendo como objeto de estudo o envelhecimento, no sentido de preparar as gerações do presente e as do futuro para um envelhecer ativo, saudável e com dignidade no bojo das cidades, para ainda aceitar a velhice como parte de um processo natural da vida, que deve ser vivido com sabedoria, 
de forma feliz e harmoniosa na família e diante da sociedade, o que significa, parafraseando o filósofo Platão, viver na paz e na tranquilidade, longe das coisas ruins do mundo.

Sócrates (469 a.C. - Atenas, 399 a.C.) ensina-nos com a sua filosofia educativa, sendo homens ou mulheres, que devemos vivenciar uma conduta virtuosa e honesta na sociedade, buscando sempre o Conhecimento, a Cultura e a Educação, para atuarmos no cotidiano problemático dos espaços terrestres, nas relações sociais de poder e de conflitos, agindo com sabedoria e prudência e estando-nos bem preparados para as situações adversas do existir humano. Desse modo, para essas pessoas que se encontram num nível elevado de consciência espiritual, política e educacional, o envelhecimento não seria problema algum, apenas um estágio da vida no qual temos que, desde a juventude, prepararmo-nos para vivermos no futuro, uma velhice de forma feliz e sadia, em um processo de envelhecimento ativo e participativo na sociedade (PLATÃO, 1985; BEAUVOIR, 1990).

Em "A República", destacamos que Platão faz referência a um diálogo de Sócrates com Céfalo, tendo como tema a velhice: na ocasião Sócrates é acompanhado por diversos jovens que o admiravam e um deles, Polemarco, convida-o para ir à casa de seu pai Céfalo. Ao chegarem à casa, Céfalo fica surpreso com a presença de Sócrates e pede desculpas por não o visitar, devido a sua velhice e por quase não sair de sua casa. Céfalo convida Sócrates para visitá-lo e afirma a seu amigo que "quanto mais os prazeres do corpo emurchecem, tanto mais crescem o desejo e o prazer da conversação". Sócrates aceitou o convite e respondeu que gostava de conversar com os velhos, pois acreditava que com os antigos estavam a resposta, ou as respostas, para a compreensão do envelhecimento, já que estes vivenciam um caminho no qual teremos que caminhar provavelmente no futuro. Sócrates questionava "o que é este caminho: será áspero e difícil, ou cômodo e fácil." Sócrates questionou ao seu amigo Céfalo como estando velho, sente-se ao alcançar esta etapa da vida que os poetas denominam de "limiar da velhice"? Céfalo respondeu que se sentia ótimo, pois o triste poema ou canção, retratado por muitos, penalizando a velhice por todos os males, para ele era proveniente do próprio existir e não da idade avançada e que a velhice significava muita paz e liberdade. Disse-lhe, ainda, que se os homens tiverem bom caráter e alma equilibrada, a velhice não será problema algum (PLATÃO, 1985; SANTOS, 2001).

O filósofo Aristóteles (384 - 322 a. C.), nascido em Estagira, Macedônia, vai aos 18 anos para Atenas e ingressa na Academia de Platão, onde se torna discípulo deste, tendo sido considerado um dos principais filósofos da época e com grande influência na organização do saber grego que colaborou e impactou a história do pensamento ocidental. Aristóteles, em relação às concepções acerca do envelhecimento, é bem diferente de seu mestre Platão, haja vista que entendia que uma boa velhice seria aquela sem enfermidades e que ser velho é extremamente deplorável, o que confirmou em sua obra "Ética a Nicômaco", onde afirma que os velhos são pessoas reticentes, hesitantes, lentas, desconfiadas, não virtuosas, que só imaginam o mal e carentes de generosidade, vivendo das lembranças do seu passado e não considerando a opinião dos outros. Aristóteles considerava, ainda, que o ser humano evoluía até os 50 anos. Desta forma, segundo ele, tais características colocavam os velhos como não capacitados, tanto para o poder na pólis (cidade-estado), como para cargos de relevância política (PLATÃO, 1985; SANTOS, 2001).

Não podemos deixar de falar do médico Hipócrates (460 - 370 a. C.), celebridade da Antiga Grécia, que é considerado "Pai da Medicina", e por trabalhar a saúde a partir de uma visão racional e científica, não considerando as superstições, crendices populares e práticas mágicas da "saúde" primitiva. Para Hipócrates, a velhice inicia-se a partir dos 50 anos e associada ao desequilíbrio dos humores. Ele estabelece diferentes características nos estados clínicos entre idosos e jovens, apontando que nos velhos, a temperatura não tende a ser alta, estes têm doenças crônicas, os hábitos intestinais transformam-se, bem como, o diagnóstico das enfermidades é diferente e difícil. Hipócrates fundamentou a sua prática e a sua forma de 
compreender o organismo humano, incluindo a personalidade na teoria dos quatro humores corporais (sangue, fleuma ou pituíta, bílis amarela e bílis negra) que, consoante às quantidades relativas presentes no corpo, levariam a estados de equilíbrio (eucrasia) ou de doença e dor (discrasia).

Com Hipócrates, foram elaborados os primeiros procedimentos médicos direcionados para os velhos e cuidados com a saúde na velhice. Ele determinou normas assistenciais, no que tange à higiene corporal; recomendou atividade física e mental e alimentação adequada, bem como moderação nas ações do cotidiano, do existir humano, o que entendemos ser o nascimento da abordagem geriátrica na Medicina e da Gerontologia.

Os gregos ofertaram ao mundo grandes conhecimentos e conceituaram o processo do envelhecimento a partir de diversas concepções. O pensamento aristotélico contribuiu para os estudos e avanços da Medicina em relação à velhice no período de transição da Antiguidade para a Idade Média (séculos II a V d. C.). Os ensinamentos medicinais de Hipócrates sobre o envelhecimento influenciaram o filósofo e médico romano Claudio Galeno, que expandiu a teoria dos humores, ligando-a a personalidade. Para ele, havia uma relação direta entre os níveis de humores no corpo e as inclinações emocionais e comportamentais, que chamou de "temperamentos", sendo estes formados por quatro elementos: fleumático/terra (fria e seca), sanguíneo/ar (quente e úmido), colérico/ fogo (quente e seco) e melancólico/água (fria e úmida). O equilíbrio dos humores determina o tipo de personalidade da pessoa, além de indicar a tendência a sofrer certas doenças. Se algum dos humores se desenvolver mais do que outros, passará a dominar a personalidade da pessoa, o que certamente alteraria o comportamento dos indivíduos, sejam novos ou velhos e, desse modo, a velhice ocorreria de forma determinada pelos temperamentos humanos.

Nessa perspectiva, sabemos que os procedimentos de ensino-aprendizagem da medicina de Hipócrates foram fundamentais para a compreensão da velhice, do envelhecimento humano e para o cuidado com a saúde dos indivíduos nesta fase da vida. Estes procedimentos proporcionaram à humanidade a estruturação da Geriatria e da Gerontologia na modernidade e, a partir desses conhecimentos, Vieira (2011) aborda sobre temas e problemas para pensar o envelhecimento:

\begin{abstract}
Até recentemente, acreditava-se que grande número dos problemas encontrados no idoso doente eram consequências normais do envelhecimento. Somente há poucos anos a abordagem geriátrica ampla e a medicina geriátrica começaram a ser estruturadas. Hoje se sabe que a tendência a rotular sintomas como "problemas da idade" é um dos principais obstáculos ao correto diagnóstico e tratamento das doenças comuns na velhice. A doença é aceita pelo paciente, pela família e muita das vezes até pelo médico como manifestação normal da idade. Os sintomas são considerados intratáveis ou não merecedores de atenção médica. Isto não é verdade. A medicina geriátrica é uma especialidade que envolve a prevenção ou a reabilitação destes problemas comuns no envelhecimento, indo além do diagnóstico e do tratamento isolados da doença. Nesta abordagem ampla, a medicina geriátrica enfatiza a qualidade de vida e a independência funcional do paciente idoso, trabalhando em conjunto com uma equipe multidisciplinar de profissionais, a equipe de gerontologia." (VIEIRA, 2011, p.7).
\end{abstract}

Vieira (2011) confirma, na modernidade, a relevância da Geriatria e da Gerontologia para a interpretação e conceituação da velhice e do processo de envelhecimento humano na sociedade, em especial, para o cuidado dos velhos e tratamento de suas doenças de forma preventiva e curativa, algo ainda muito recente na Medicina, mas, com o avanço da ciência e da tecnologia, o fenômeno do envelhecimento tem ganhado maior ênfase e sido foco de diversos estudos científicos, em diversas áreas do conhecimento da ciência que agora se expressa na Gerontologia. 
No Século I, antes da Era Cristã, destaca-se a figura do emblemático romano Marco Túlio Cícero (106 - 33 a. C.) que foi advogado, político, escritor, orador e filósofo da gens Túlia (família da Roma) da República Romana, que se elege cônsul em 63 a. C. A sua família lhe proporcionou uma educação de qualidade. Marco Túlio estudou na escola pública e ao completar a maioridade, passou a vestir a toga virilis (traje masculino). O seu pai Cícero (o velho) lhe entrega aos cuidados do célebre Senador e jurista romano Quinto Múcio Cévola, que o pôs a par das Leis e das Instituições Políticas de Roma. Cícero é educado com base nos ensinamentos dos antigos filósofos, poetas e historiadores gregos, considerado o primeiro romano que chegou aos principais postos do Governo, com base na sua eloquência e ao mérito com que exerceu as suas funções de magistrado civil (PLATÃO, 1985, SANTOS, 2001).

Cícero, na antiguidade (44 a. C.), em suas reflexões sobre o envelhecimento, acaba escrevendo o livro "De Senectute ou Catão, o velho", que é apresentado em forma de dissertação e dedicado ao seu amigo Tito Pompônio Ático. A obra descreve um diálogo entre o idoso Marco Catão, considerado modelo máximo da cultura romana, e os jovens, homens públicos: Lélio e Cipião, em que a velhice é o tema abordado. Ressalta-se que Cícero e Tito estavam próximos de vivenciar a velhice, que é tratada no texto. Neste, Cícero defende e conceitua a velhice como algo bom ou ruim e isto, dependendo do agir do indivíduo na Natureza. Demonstra, também, a dualidade existente no processo do envelhecimento humano, a oposição dialética entre velhice e juventude que poderá ocorrer no ser de forma positiva ou negativa (PLATÃO, 1985, SANTOS, 2001).

Em "De Senectude", os jovens Cipião e Lélio interrogam Marco Pórcio Catão (234 149 a.C.) sobre o envelhecimento, com relação às consequências e vantagens do envelhecer. $\mathrm{O}$ Senador Catão, já com 80 anos, reponde, derruba os tabus e preconceitos contra a velhice e coloca os velhos em posição de destaque, como grandes responsáveis pela restauração dos Estados quando arruinados pelos jovens (PLATÃO, 1985; SANTOS, 2001).

Conforme Catão, a velhice é acusada, por muitos, de ser uma fase da vida deplorável pelos seguintes motivos: a) afasta o homem dos negócios; b) torna o corpo mais sujeito a doenças; c) priva o homem de quase todos os prazeres e d) não está muito distante da morte. Catão elaborou, então, a defesa da velhice e, pela lógica de sua argumentação, afirma que o envelhecimento poderá ocorrer de forma feliz, que dependerá exclusivamente do seu modo de vida e de viver na sociedade. Considerando, também, que a velhice digna é uma edificação árdua que exige bastante vigor e uma prática dialética virtuosa entre jovens, adultos e velhos e que todos da sociedade devem respeitar e aceitar as diretrizes da natureza para viverem a excelência de suas idades e com felicidade.

A obra de Cícero (44 a. C) é um instrumento, um manual de orientação para jovens e velhos que objetivam uma existência feliz e harmoniosa com a natureza, livres do embate de gerações. Cícero considera o envelhecimento um processo fisiológico, uma fase natural da vida, na qual os indivíduos estão sujeitos à redução da memória e da capacidade funcional, como alteração nos órgãos dos sentidos e diminuição da capacidade laboral. Destacou que quando se chega à velhice, os prazeres corporais paulatinamente cedem lugar aos projetos intelectuais e enfatizou a necessidade de prestigiarmos os velhos e de prepará-los psicologicamente para o fim da vida. Entretanto, Cícero defendia a tese de que, para se viver uma velhice saudável e prazerosa, seria fundamental o cuidado corporal, nutricional, mental, a inserção em projetos educacionais e outras atividades que gerassem benefícios individuais e coletivos, todavia que fosse de acordo com a condição física de cada ser.

Dessa forma, ele dizia que a arte de envelhecer está em descobrirmos a alegria que todas as fases da existência humana nos proporcionam, seja enquanto criança, jovem, adulto ou velho, haja vista que todas são cheias de virtudes. O processo de ensino-aprendizagem do envelhecer saudável, ativo e feliz se dá no convívio social, na coletividade e na participação com o outro, com seu irmão velho na comunidade, no trabalho, nas escolas e igrejas, conforme as suas 
escolhas no meio natural, no espaço onde vive (urbano ou rural), e respeitando a Mãe Natureza (PLATÃO, 1985, SANTOS, 2001).

Cícero $(1999 ; 2006)$, ainda em sua obra, afirma que não podemos atribuir à velhice todos os males da vida e que quem vive se lamentando, certamente fez o mesmo nas outras idades. Neste aspecto, ele refere-se que os humanos inteligentes devem sempre se distanciar da tristeza e do mau humor, desses temperamentos que são prejudiciais em qualquer fase da vida. $\mathrm{Na}$ concepção estóica de Cícero, a velhice deve ser aceita por todos, pois é uma determinação da natureza, processo fisiológico que abraçará a todos. Assim, estudar e pesquisar o fenômeno, a questão social e educacional do envelhecimento é fundamental para se pensar as condições da velhice na contemporaneidade, em especial, no Brasil, no Estado do Tocantins e na cidade de Araguaína.

O romano Lúcio Aneu Séneca ou Sêneca (20 a. C - 65 d.C.) foi um dos mais relevantes advogados, escritores e intelectuais do Império Romano. Ele refletiu sobre o envelhecimento em seus escritos e destacou várias cartas destinadas a seu amigo Lucílio (no período entre 63 e 65 d. C.). Segundo Sêneca, a velhice não seria algo ruim, mas uma coisa boa, já que faz parte do processo da natureza humana que deve, com tranquilidade, ser aceita e ocorrer vivendo-a de forma feliz, com sabedoria, prudência e no culto às virtudes para o bem viver. Dessa forma, Sêneca respaldou o pensamento de Cícero em relação ao envelhecimento humano (PLATÃO, 1985).

\section{CONSIDERAÇÕES FINAIS}

É de suma importância conhecer a visão dos antepassados por meio dos filósofos. A história oportuniza-nos enxergar o outro e a nós mesmos. Nesta perspectiva, o amor dos filhos aos pais envelhecidos é algo divino, especial, que compreende maior proteção e segurança na última fase da vida humana, o que se considera um dos mais admiráveis atos da raça humana consigo mesma e para com seus semelhantes, em destaque com a sua geração e para com as futuras gerações.

Assim, a velhice e o envelhecimento, tanto nas cidades da antiguidade, como nas cidades do atual mundo moderno colonizado e capitalizado, são vistos de forma idêntica: algo negativo, uma coisa ruim que, para muitos, expressam terror e como se a velhice não fosse atingir a todos. Por outro lado, existem outras visões de caráter positivo e que devem ser consideradas.

Desse modo, adaptarmo-nos a esta nova fase do existir humano, a velhice, é algo que requer cuidados e mudanças de hábitos, em especial, no tratamento da nossa saúde. Além da saúde, é preciso priorizar outras áreas: sociais, esportivas e educativas, nas quais a participação e inserção dos velhos são essenciais para o bem-estar social e a melhoria da qualidade de vida deles. É preciso, também, que as autoridades governamentais e o Estado brasileiro se responsabilizem pelas políticas públicas voltadas à população idosa.

Atualmente, chamam-nos a atenção algumas áreas, específicas, da Medicina e da Educação, cujo foco é a preparação das gerações para a velhice, para a construção de um envelhecimento digno, participativo e ativo na sociedade: a Gerontologia, a Geriatria, as Universidades da Terceira Idade (UNATIs) e a Universidade da Maturidade (UMA).

Portanto, a questão do envelhecimento humano e da velhice é temática viva e presente no século XXI e que precisa ser pesquisada e estudada profundamente em nossa Amazônia brasileira, em toda a região norte, em especial no Estado do Tocantins.

\section{REFERÊNCIAS}


ALMEIDA, V. L. V. Imagens da velhice: o olhar antropológico. A terceira idade, São Paulo: v. 10, n. 15, p 35-40, dez. 1998.

AMARO, Sarita. Serviço Social na Educação: bases para o trabalho profissional. $1^{\text {a }}$ reimpressão - Florianópolis: Ed. Da UFSC, 2012.

ARROYO, Miguel G. Outros Sujeitos, Outras Pedagogias. Petrópolis, RJ: Vozes, 2012.

ASLAN, Ana, 1898. Vencendo a velhice. Tradução José Augusto Carvalho. $5^{\text {a }}$ ed. Rio de Janeiro: Record, 1994. 127p. Tradução de: Contre la vieillesse.

BEAUVOIR, S. de. A velhice: realidade incômoda. $2^{\mathrm{a}}$ ed. DIFEL, São Paulo: 1976.

BEAUVOIR, Simone de (1908 - 1986). A velhice. Tradução de Maria Helena Franco Martins. $2^{\text {a }}$ ed. - Rio de Janeiro: Nova Fronteira, 2018.

BRANDÃO, Carlos Rodrigues. O que é educação. 33 ed. - São Paulo: Brasiliense, 1995. (Coleção primeiros passos; 20).

BRASIL. Constituição da República Federativa do Brasil: promulgada em 05 de outubro de 1988. São Paulo: Saraiva, 1988.

BRASIL. Estatuto da Pessoa Idosa. - Lei 10.741 de 1/10/2003 - Dispõe sobre o Estatuto do Idoso e dá outras providências. Autor da lei: Senador Paulo Paim PT/RS - Brasília, 2003.

CÍCERO, M. T. Saber envelhecer. Tradução. Paulo Neves. Porto Alegre: L \& PM, 1999.

CÍCERO, M. T. A Velhice Saudável: O Sonho de Cipião. Tradução Luiz Feracine. São Paulo: Escala, 2006. 112 p. Tradução de: De senectude.

CONFÚCIO. Vida e doutrina, Os Analectos. Tradução de Múcio Porphyrio Ferreira. São Paulo: Pensamento, 1999.

FALEIROS, Vicente de Paula. Cidadania e direitos da pessoa idosa. Ser Social. In: Revista do Programa de Pós Graduação em Política Social. Brasília, UNB, n. 20, jan./jun. 2007. 35-61 p.

LAO TZU. Tao te Ching. (Tradução e comentários de Laércio B. Fonseca. (2.ed) Editora: Lenon Tree, 2014 / Limeira-SP.

OLIVEIRA, Rita de Cássia da Silva; SCORTEGAGNA, Paola Andressa; OLIVEIRA, Flávia da Silva. $O$ envelhecimento e a velhice: teorias, demografia e política. $1^{\mathrm{a}}$ ed. Curitiba, PR: CRV, 2011. 100p.

PESSANHA, Clarice C. Franco. Breves considerações sobre a evolução histórica da imagem do Idoso na Civilização Oriental. Revista de Trabalhos Acadêmicos - Universo Campos dos Goytacazes, n. 6, Vol. 2, 2016. Disponível em: http://www.revista.universo.edu.br/index.php?journal=1CAMPOSDOSGOYTACAZES2\&pa ge=issue \&op=view\&path $\% 5 \mathrm{~B} \% 5 \mathrm{D}=176 \&$ path $\% 5 \mathrm{~B} \% 5 \mathrm{D}=$ showToc. Acesso em: 14 de jun. 2019. 
PLATÃO (427 - 347 a. C.). A República. Platão; tradução de Carlos Alberto Nunes. - 3. Ed. - Belém: EDUFPA, 2000.

PLATÃO. A República. Tradução de Elza Moreira Marcelina. Brasília: UnB, 1985. Livro 7.

SANTOS, S. S. C. Envelhecimento: visão de filósofos da antigüidade oriental e ocidental. Rev. Rene., Fortaleza, v.2, n.1, p. 88-94, jul./dez. 2001.

TAO TE CHING. Tradução de Wu Jyh Cherng. Rio de Janeiro: Mauad, 2011.

VIEIRA, Cláudia Caciquinho. IDOSO E AMEDICINA: diálogo com a abordagem geriátrica ampla. In: MOREIRA, Jacqueline de Oliveira (Org.). Gerontologia e cuidado: temas e problemas para pensar o envelhecimento. Gerontologia e cuidado: temas e problemas para pensar o envelhecimento. Curitiba, PR: CRV, 2011. 